\title{
Erratum: Connecting genetic risk to disease end points through the human blood plasma proteome
}

Karsten Suhre, Matthias Arnold, Aditya Mukund Bhagwat, Richard J. Cotton, Rudolf Engelke, Johannes Raffler, Hina Sarwath, Gaurav Thareja, Annika Wahl, Robert Kirk DeLisle, Larry Gold, Marija Pezer, Gordan Lauc, Mohammed A. El-Din Selim, Dennis O. Mook-Kanamori, Eman K. Al-Dous, Yasmin A. Mohamoud, Joel Malek, Konstantin Strauch, Harald Grallert, Annette Peters, Gabi Kastenmüller, Christian Gieger \& Johannes Graumann

Nature Communications 8:14357 doi: 10.1038/ncomms14357 (2017); Published 27 Feb 2017; Updated 11 Apr 2017

The original version of the Supplementary Information attached to this Article did not include Supplementary Note 1. The HTML has now been updated to include a corrected version of the Supplementary Information.

This work is licensed under a Creative Commons Attribution 4.0 International License. The images or other third party material in this article are included in the article's Creative Commons license, unless indicated otherwise in the credit line; if the material is not included under the Creative Commons license, users will need to obtain permission from the license holder to reproduce the material. To view a copy of this license, visit http://creativecommons.org/licenses/by/4.0/

(C) The Author(s) 2017 